\title{
The panty hose caper
}

\author{
Joy Rockenbach, Rod Himon, David Bourne
}

Arkansas Department of Health $4815 \mathrm{~W}$ Markham, MS-3, Little Rock, Arkansas 72205, USA

J Rockenbach

R Himon

D Bourne

Correspondence to David Bourne.

The opinions expressed herein are those of the authors and do not necessarily reflect those of the Arkansas Department of Health.
Magazines which advertise cigarettes often omit from stories on health any information on the harmful effects of smoking. ${ }^{1,2}$ Publishers apparently fear that cigarette companies will buy fewer ads in their magazines if they report on the link between smoking and disease. This omission of information on smoking-related disease is a type of self-censorship.

Self-censorship may be seen not only in the editorial policy of magazines, but in marketing for other consumer goods. We present an example of self-censorship in marketing for women's hosiery.

Recently, some Hanes hosiery products have included a package insert "Created by Glamour and funded by Hanes Hosiery", as part of a national breast-health programme (see figure). The insert gives instruction in how to perform breast self-examination. It also advises patrons to eat more fruit and vegetables, reduce fat in the diet, exercise regularly, have an annual clinical breast examination, and obtain a mammogram when indicated. No advice is given to stop smoking or not to start smoking.

Hanes and Glamour magazine deliver a worthwhile health message on breast-health and "other things you can do for good health". If the insert were on a single topic (breasthealth), the omission of a health warning on smoking would be more understandable and perhaps reasonable. However, by failing to mention smoking in the broad range of topics covered (low-fat diet, fruit and vegetables, beans and whole grains, exercise, mammography), they are self-censoring. Glamour publishes cigarette ads, conducts biased surveys on "smokers' rights", and avoids reporting on the link between smoking and disease. $^{3-5}$ Glamour denies that cigarette advertising influences their health coverage. ${ }^{6}$

Not smoking is far more effective in preventing death from cancer than breast selfexamination, a low-fat diet, or exercise. The importance of the message to avoid smoking is underscored as lung cancer annually kills more US women than breast cancer. Early detection of breast cancer can reduce mortality by $30 \%$ ? while not smoking will prevent $87 \%$ of lung cancers from ever developing. ${ }^{8}$

At the bottom of the package insert appear the emblems of collaborating agencies: the National Cancer Institute (NCI) and the American Health Foundation (AHF). By allowing the use of their emblems, these agencies give explicit approval to these health messages and implicit approval to the omission of advice about not smoking. It would be regrettable if these agencies consciously approved of this omission.

Also implicit in this message to the consumer is the notion that Hanes, Glamour, the NCI, and $\mathrm{AHF}$ are joined to improve the health of the public. Hanes and Glamour receive a boost to their public image, appearing as responsible corporate citizens interested in the health of their consumers. At the same time, they are safeguarding their income from tobacco advertisers through this act of self-censorship.

Health advocates must be alert for other examples of self-censorship and should expose this seamy side of product marketing.

1 Warner KE, Godenhar LM, McLaughlin CG. Cigarette advertising and magazine coverage of the hazards of smoking: a statistical analysis. $N$ Engl $f$ Med 1992; 326: 305-9.

2 Amos A, Jacobson B, White P. Cigarette advertising policy and coverage of smoking and health in British women's and coverage of smoking and healt

3 Whelan EM. Alarm clocks can kill you. Have a smoke. New York Times, 8 September 1992.

4 Whelan EM. Bird droppings or cigarette smoking ... Which causes lung cancer? or, Why magazines which report on health must discontinue cigarette advertising. Priorities 1993; Fall/Winter: 17-9.

5 Davis RM. How to load a survey - the Glamour way. Tobacco Control 1994; 3 : 103-4.

6 Whitney R. Letters. Priorities 1994;6: 45-6.

7 Fletcher SW, Black W, Harris R, Rimer BK, Shapiro S. Report of the International Workshop on Screening for Breast Cancer. F Natl Cancer Inst 1993; 85:1644-56.

8 American Cancer Society. Cancer facts \& figures - 1994. Atlanta, Georgia: American Cancer Society, 1994; 22. 


\section{ood looks start with good health..}

What you do today and throughout the year can make a difference. in your future-that's the message of Glamour/Hanes Hand in Hand, a national breast-health program. For example, by examining your breasts once a month*, you can learn what is normal for your breasts and how they change from time to time.
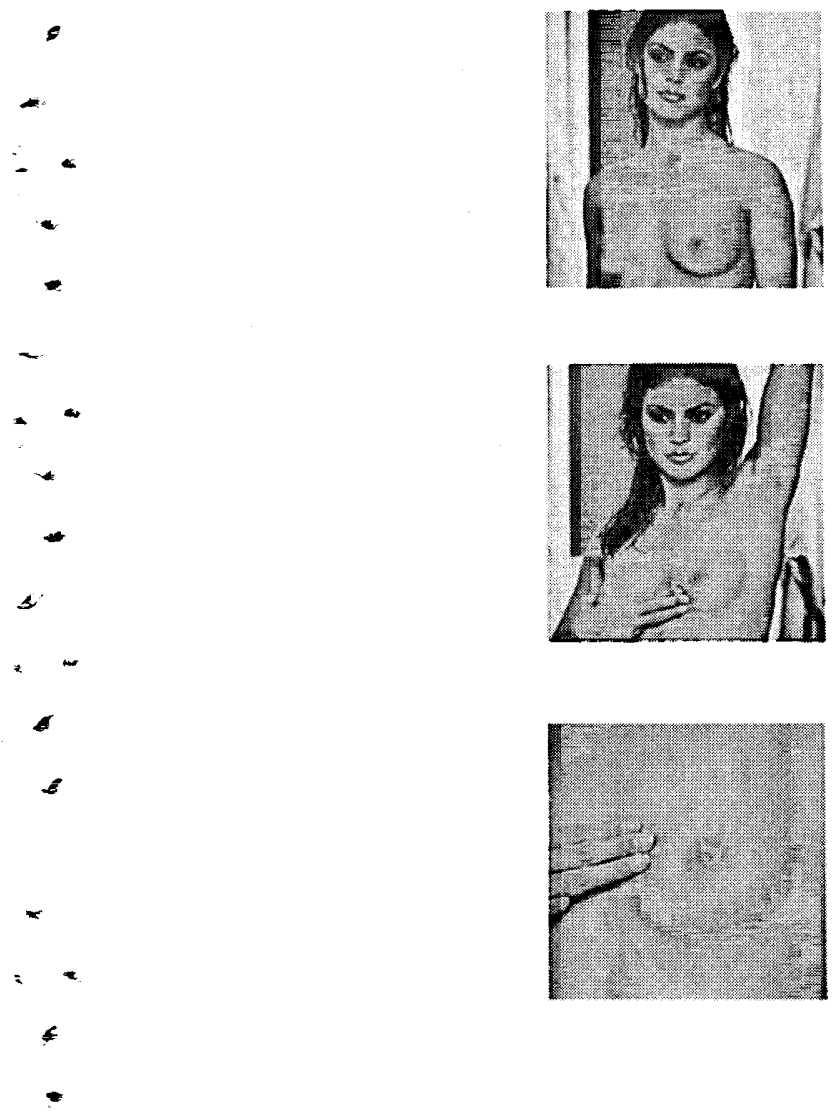

$$
<
$$$$
\vdots
$$
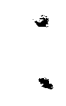

- Standing before a mirror, insped both breasts for anything untusual-a dis. charge from the nipples; an inverted nipple: puckering dimpling or scaling of the skin: any change in the shape or contour of your breasts. Still looking in the mirror, repeat with your hands clasped behind your head and with hands pressed on hips.

2.

Examining breasts while in the shower or with powder or lotion reveals changes easily. Raise your left arm. Press right hand in small circles on your left breast. Move fingers in circles slowly around the entire breast. If you prefer, move your fingers up and doum in vertical lines.

15 Start examining your breasts at the outer edge; work loward the nipple. covering the entire breast, including the underarm area and up to the collarbone. Next, raise your right arm and examine your right breast with yourleft hand. Repeat the exam lying down. If you find anything unusual, contact your doctor right away.

The best time ts two to three days after the end of your menstrual pertod. If you anen't mensenneting plck an easy toremember datc. such as the first of the month. If you are taking hor.

\section{cunnovi: fanes. HANDHAN'}

Creited by Gemour end funded by Henca thoskry

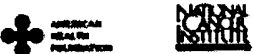
the flat part of three or four fingers of your

Other things you can dofor good health:

Eat more fruts and vegetables, beans and whole gratins.

Reduce the fat in yourdiet.

Exerctse regularly.

Have a heallh professtomal evamine your breasts once a year.

Ask your health professional how to examine your breasts yourself. Also ask when you should have a mammogram. Guidelines for most women Gollow your doctors specific recommendations: Ages 40.49 , every $1-2$ years; age so and over, annually.

Formore informatton oall the Cancer Information Service 1-800-4-CANCER USA. ONLY

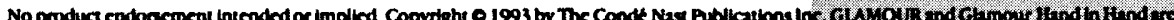

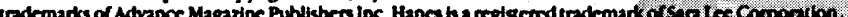

